\title{
Combination or Alone? Which one is the Best in Premature Ejaculation Treatment?
}

\author{
Aykut Buğra Şentürk¹, Ali Haydar Yılmaz², Basri Çakıroğlu³, (i) Muhammet Yaytokgil5,

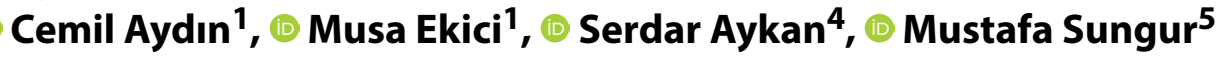 \\ ${ }^{1}$ Department of Urology, Hitit University, Corum, Turkey \\ ${ }^{2}$ Department of Urology, Bilecik State Hospital, Bilecik, Turkey \\ ${ }^{3}$ Department of Urology, Hisar Intercontinental Hospital, Istanbul, Turkey \\ ${ }^{4}$ Department of Urology, University of Health Sciences Turkey, Hamidiye Faculty of Medicine, Haydarpaşa Numune Health Application \\ and Research Center, Istanbul, Turkey \\ ${ }^{5}$ Department of Urology, Hitit University Erol Olcok Training and Research Hospital, Corum, Turkey
}

\begin{abstract}
Introduction: To compare the effectiveness of tadalafil alone and in combination with dapoxetine in patients with premature ejaculation.

Methods: In this study, 120 patients treated at the urology clinic for premature ejaculation were evaluated prospectively. IELT and IIEF forms of patients were filled before this study, and their urological examinations were performed. Patients that were being treated were divided into two groups. Patients in group 1 received only $5 \mathrm{mg}$ tadalafil, whereas patients in group 2 received a combination of dapoxetine $30 \mathrm{mg}$ and tadalafil $5 \mathrm{mg}$.

Results: After the treatment, group 1 mean IEFF scores were 25.12 \pm 2.49 , and mean IELT scores were $7.35 \pm 4.37$ seconds. There was a statistically significant increase in both parameters $(p<0.001)$. After the treatment, group 2 mean IEFF scores were $27.37 \pm 2.46$, and mean IELT scores were $9.07 \pm 4.20$ seconds. There was a statistically significant increase in both parameters $(p<0.001)$.

Discussion and Conclusion: Use of dapoxetine in combination with tadalafil instead of using tadalafil alone in the treatment of premature ejaculation will increase treatment success.

Keywords: Combination; dapoxetine; premature ejaculation; tadalafil.
\end{abstract}

$\mathrm{T}$ hree major forms of male sexual dysfunctions are known as erectile dysfunction, ejaculatory dysfunction, and a decrease in libido. According to a large number of epidemiological studies, premature ejaculation (PE) is the most widely seen male sexual dysfunction and its prevalence is between $20-40 \%$. Premature ejaculation is an ejaculation condition with insufficiently controlled or totally uncontrolled ejaculation before or shortly after the sexual intercourse as a result of stimulating the person ${ }^{[1]}$.

Premature ejaculation has two types, as primer/lifetime and seconder/acquired. Although the etiology has not been completely acknowledged, anxiety disorder accompanying to penile hypersensitivity, as well as $5 \mathrm{HT}$ receptor dysfunctions, are the most accepted theories.

Correspondence (İletişim): Aykut Buğra Şentürk, M.D. Hitit Universitesi Corum Egitim ve Arastirma Hastanesi Uroloji Bolumu 19300 Corum, Turkey Phone (Telefon): +90 5323633237 E-mail (E-posta): aykutbugra@gmail.com 
Intravaginal Ejaculation Latency Time (IELT) is the ejaculation time that can be measured with a chronometer or based on estimation. While measurement with chronometer has the advantage of measuring more objectively, IELT measured by self-estimation and chronometer can accurately determine the duration of premature ejaculation with $80 \%$ sensitivity and $80 \%$ specificity ${ }^{[2]}$.

The 5-hydroxy tryptamine (5-HT) neurotransmitter has been shown to play an important role in the ejaculation control process. In at least three subgroups, studies have shown that the $5-\mathrm{HT}$ receptor is widely distributed in the seminal vesicle, vas deferens, lumbosacral, and thoracic spinal cord ${ }^{[3,4]}$.

When all this pathophysiology is evaluated, several proposed pharmacotherapies for the treatment of premature ejaculation include topical agents, creams, sprays, and systemic therapies.

The use of serotonin in the treatment of premature ejaculation has been widespread nowadays since it has been determined that serotonin is inhibiting the ejaculation in different ways and accomplishing this procedure via SSRIs [5]. Six different agents, i.e., citalopram, fluoxetine, fluvoxamine, paroxetine, sertraline, and a new drug dapoxetine, are used in the systematic treatment ${ }^{[6]}$.

Recently, selective serotonin reuptake inhibitors, such as dapoxetine and paroxetine, have been used as first-line treatment in the treatment of premature ejaculation, and dapoxetine has been used specifically in the treatment of premature ejaculation in many countries ${ }^{[7]}$.

\section{Materials and Methods}

Between January 2014 and June 2015, 120 patients treated at a urology clinic for premature ejaculation were evaluated prospectively. This study was conducted only after the approval of the local ethics committee of Hisar Intercontinental Hospital was acquired (No: 2018/345). Patients with life-long premature ejaculation and less than two minutes of IELT were included in this study.

Intravaginal Ejaculation Latency Time (IELT) and International Index of Erectile Function (IIEF) forms of patients were filled, and their urological examinations were performed before this study. Organic problems causing erectile dysfunction were investigated. Patients with erectile dysfunction due to organic problems were excluded from this study. In addition to this, patients with drug use due to psychiatric disorders, with genitourinary tract infections and with chronic drug use history that may affect ejaculation, were not included in this study. Patients that are being treated were divided into two groups. Patients in Group 1 received only $5 \mathrm{mg}$ tadalafil, whereas patients in Group 2 received a combination of dapoxetine $30 \mathrm{mg}$ and tadalafil $5 \mathrm{mg}$. Patients were recalled for their controls in the $1^{\text {st }}, 3^{\text {rd }}$, and $6^{\text {th }}$ months for their re-evaluations. Both groups were evaluated concerning treatment success, treatment compliance, and side effects. IEFF and IELT forms of patients were filled before and after the treatment to measure the success of the treatment.

\section{Results}

Before the treatment, the mean age of the patients in Group 1 was $39.2 \pm 5.1$, the mean IEFF score was 20.87 \pm 3.27 , and the mean IELT score was $1.49 \pm 0.57$ minutes. The mean age of the patients in Group 2 was 36.2 \pm 3.9 , the mean IEFF score was $20.80 \pm 3.10$, and the mean IELT score was $1.47 \pm 0.57$ minutes. There was no statistical difference between the pre-treatment age, IEFF and IELT scores of both groups. After the treatment, Group 1 mean IEFF score and mean IELT score were $25.12 \pm 2.49,7.35 \pm 4.37$ seconds, respectively. There were statistically significant increases in both parameters $(p<0.001)$. After the treatment, Group 2 mean IEFF score was $27.37 \pm 2.46$ and the mean IELT score was $9.07 \pm 4.20$ seconds. There was a statistically significant increase in both parameters $(p<0.001)$. The IEFF increase was significantly higher in Group 2 than in Group 1 ( $p=0.001)$, and again, there was a statistically higher increase in Group 2 for IELT as well ( $p=0.045$ ) (Table 1, 2).

\section{Discussion}

Premature ejaculation is the most widely seen male sexual dysfunction. No consensus was reached on the treatment of the disease. In a study conducted by Lujan et al., ${ }^{[8]} 15 \%$

Table 1. IIEF alteration of the groups

\begin{tabular}{lccccccc}
\hline Group & $\mathbf{n}$ & Mean & SD & Median & Minimum & Maximum & p \\
\hline Tadalafil & 60 & 4.2500 & 3.53493 & 5.0000 & -1.00 & 11.00 & 0.001 \\
Tadalafil+daposketin & 60 & 6.5667 & 3.50480 & 6.0000 & 0.00 & 13.00 \\
\hline
\end{tabular}

SD: Standard deviation. 
Table 2. IELT alteration of the groups

\begin{tabular}{lccccccc}
\hline Group & $\mathbf{n}$ & Mean & SD & Median & Minimum & Maximum & p \\
\hline Tadalafil & 60 & 5.8583 & 4.47128 & 4.0000 & 0.00 & 14.50 & 0.045 \\
Tadalafil+daposketin & 60 & 7.5917 & 4.26306 & 8.0000 & 0.00 & 14.00 \\
\hline
\end{tabular}

SD: Standard deviation.

of the patients who were consulting for premature ejaculation were found to have received incorrect treatment and prescription when evaluated according to the guidelines.

In the conducted studies, combination treatment to the patients with premature ejaculation and concomitant erectile dysfunction complaints is likely to reduce the stress factor of erectile dysfunction ${ }^{[9]}$. This suggests that this rectification is likely to be done with the decrease in the performance anxiety as a secondary [reaction] to the improvement of erection, the need for more stimulation to reach the ejaculation threshold and ejaculation time improvement due to this reason. Our purpose in conducting this study about premature ejaculation and erectile dysfunction is to contribute to the literature about these diseases, which are seen frequently in sexual dysfunctions and require new research on the treatment. Thus, we have compared the effects of using only tadalafil and using dapoxetine in addition to tadalafil on patients who complained about premature ejaculation in our study. According to the results of our study, combination therapy provided a statistically significant improvement in both IEFF $(p<0.001)$ and IELT $(p<0.001)$ compared with using only tadalafil.

Sildenafil, a PDE 5 inhibitor, has been extensively examined in the treatment of premature ejaculation in the literature. Although sildenafil is not increasing IELT considerably, while decreasing the anxiety and the time to have a second erection after the ejaculation, it increases the perception of ejaculation control and sexual satisfaction ${ }^{[10]}$.

In a study of premature ejaculation in which the use of a combination of selective serotonin reuptake inhibitors and phosphodiesterase type 5 inhibitors was examined, this combination therapy was shown to have a prolonged ejaculation time that was significantly longer than that of selective serotonin reuptake inhibitors alone ${ }^{[11]}$.

In a randomized, double-blind, placebo-controlled study in which tadalafil and fluoxetine were evaluated, it was reported that the combination of fluoxetine plus tadalafil significantly increased IELT in life-time premature ejaculation cases and this increase was significantly superior to placebo $(p<0.001)^{[12]}$.
In a single-blind placebo-controlled study, usage of singledose $5 \mathrm{mg}$ tadalafil daily for six weeks has been shown to be effective and well-tolerated in the treatment of premature ejaculatory patients ${ }^{[13]}$. In another study, in a significant percentage of patients after using chronic tadalafil for six months, a reduction in sexual function changes, such as premature ejaculation, was observed ${ }^{[14]}$. When the lidocaine anesthetic spray was used in addition to the tadalafil, an increase in mean IELT was achieved ${ }^{[15]}$. In a study in which tadalafil was not used alone but in combination with paroxetine, it was reported that patients who received combination therapy had higher and sustained IELT scores in the third and sixth months ${ }^{[1]}$.

Various studies have been carried out on premature ejaculation with tadalafil. For example, in a study carried out by Özcan et al., it was determined that single-dose $5 \mathrm{mg}$ tadalafil usage in males with premature ejaculation provides a significant increase in IELT by developing the ejaculation control perception, increasing sexual satisfaction, and being beneficial on the personal stress related to ejaculation. However, as noted by the authors, the role of PDE 5 inhibitors in premature ejaculation is controversial ${ }^{[16]}$.

The possible mechanism of premature ejaculation recovery is through contraction and relaxation of the vas deferens, seminal vesicle, prostate, and urethra muscles on the NO/cGMP pathway and inhibition of peripheral adrenergic transmission. Another mechanism may be the extension of the erection time ${ }^{[17-19]}$.

According to a recent meta-analysis by Corona et al., [20] the association between premature ejaculation and erectile dysfunction, as well as premature ejaculation, increased the risk of erectile dysfunction by an average of four-fold. In addition, this risk was significantly higher in patients with depression and anxiety symptoms.

In cases of premature ejaculation in which erectile dysfunction is not associated, the whereabouts of phosphodiesterase type 5 inhibitors are not precise. In our study, the preference of tadalafil as a phosphodiesterase type 5 inhibitor is due to its long effects and the lack of interaction with dapoxetine, which is developed for premature ejaculation. In a study by Dresser et al., ${ }^{[21]}$ dapoxetine did not in- 
teract with tadalafil but found that sildenafil increased the AUC (Area under the curve) of dapoxetine by $22 \%$, but it was determined that this effect was clinically insignificant.

When the literature is reviewed, to our knowledge, there are no studies that examine the effects of the combination of tadalafil and dapoxetine on erectile dysfunction. In this study we conducted, statistically significant IEFF and IELT increases were detected in the combination group (Figs. $1,2)$. According to the published studies, $22-30 \%$ of the patients with erectile dysfunction have concurrent complaints of premature ejaculation [22].

However, the point that needs to be focused here is that, in the present study, the IEFF score was found to be higher in the combination group. That is, combination therapy

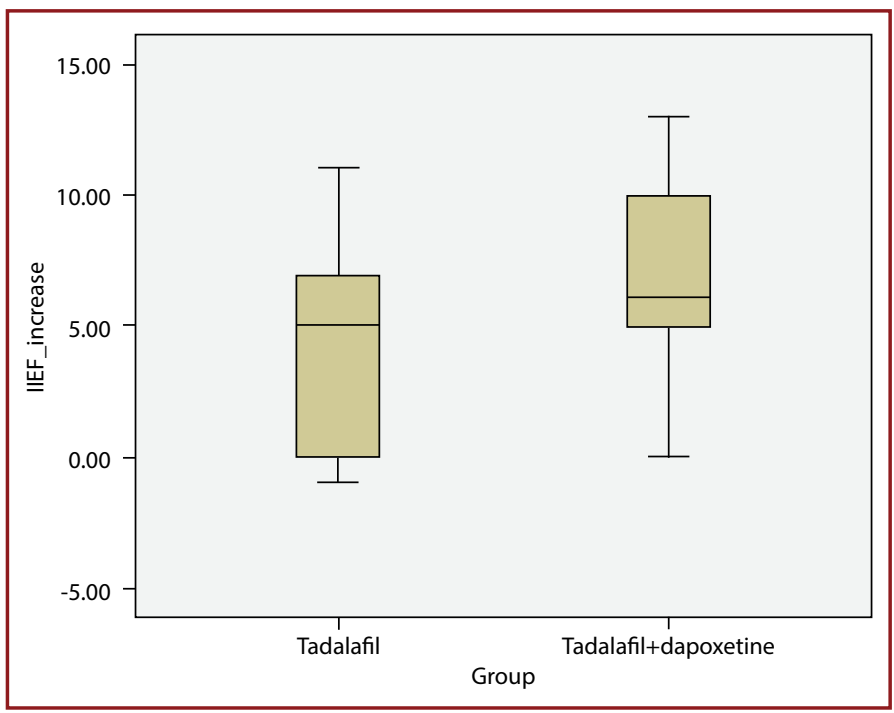

Figure 1. Box Plot graph of IIEF increase by the groups.

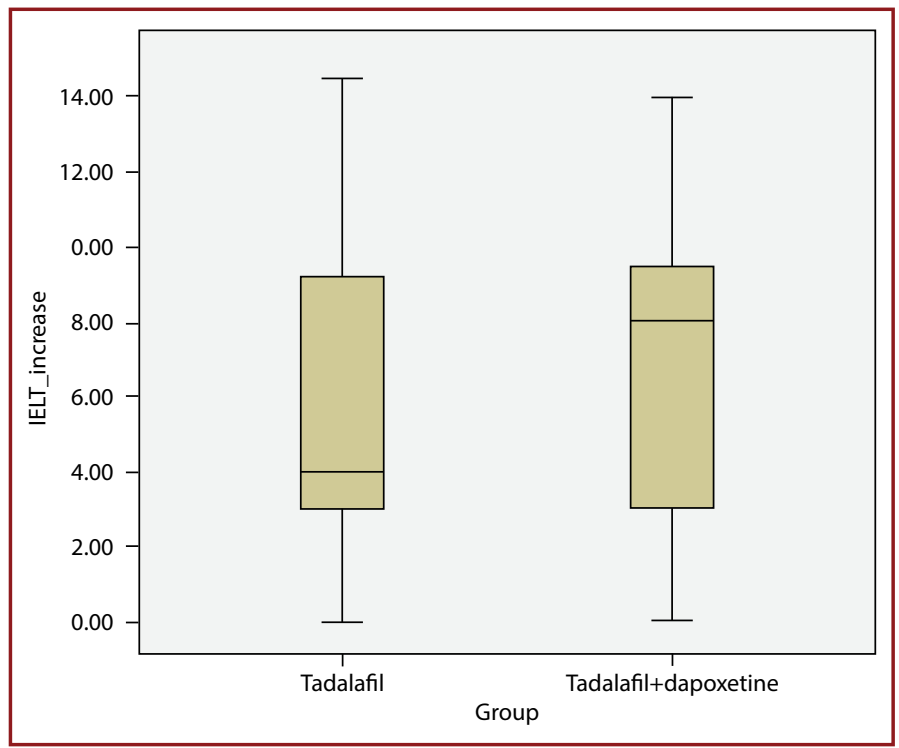

Figure 2. Box Plot graph of the IELT increase by groups. affected the IEFF score positively by treating erectile dysfunction existing in some of the premature ejaculatory patients. This is because dapoxetine reduces performance stress and allows one to control ejaculation more easily, and thereby, increase sexual satisfaction. In conclusion, our study demonstrated that the use of dapoxetine in addition to tadalafil in patients with premature ejaculation provides clinically significant results both on the IEFF score and IELT score. Although our study has some limitations, such as lack of a control group and not designed blind, we believe that our results will contribute to the literature.

\section{Conclusion}

The use of dapoxetine, in combination with tadalafil instead of using tadalafil alone in the treatment of premature ejaculation, will increase treatment success.

Ethics Committee Approval: This study was conducted after the approval of the local ethics committee of Hisar Intercontinental Hospital (No: 2018/345).

Peer-review: Externally peer-reviewed.

Authorship Contributions: Concept: A.B.Ş.; Design: A.B.Ş., B.Ç., M.E.; Data Collection or Processing: A.B.Ş., B.Ç.; Analysis or Interpretation: A.B.Ş.; Literature Search: A.B.Ş., A.H.Y., M.Y., M.S.; Writing: A.B.Ş., C.A., S.A.

Conflict of Interest: None declared.

Financial Disclosure: The authors declared that this study received no financial support.

\section{References}

1. Moudi E, Kasaeeyan AA. Comparison Between Tadalafil Plus Paroxetine and Paroxetine Alone in the Treatment of Premature Ejaculation. Nephrourol Mon 2016;8:e32286. [CrossRef]

2. Rosen RC, McMahon CG, Niederberger C, Broderick GA, Jamieson C, Gagnon DD. Correlates to the clinical diagnosis of premature ejaculation: results from a large observational study of men and their partners. J Urol 2007;177:1059-64.

3. Waldinger MD. Lifelong premature ejaculation: from authority-based to evidence-based medicine. BJU Int 2005;95:191.

4. Lasker GF, Halis F, Gokce A. Selective serotonin reuptake inhibitors for premature ejaculation: review of erectile and ejaculatory side effects. Curr Drug Saf 2014;9:118-26. [CrossRef]

5. Giuliano F, Clément P. Serotonin and premature ejaculation: from physiology to patient management. Eur Urol 2006;50:454-66. [CrossRef]

6. Montague DK, Jarow J, Broderick GA, Dmochowski RR, Heaton JP, Lue TF, et al; AUA Erectile Dysfunction Guideline Update Panel. AUA guideline on the pharmacologic management of premature ejaculation. J Urol 2004;172:290-4. [CrossRef]

7. Althof SE, McMahon CG, Waldinger MD, Serefoglu EC, Shindel AW, Adaikan PG, et al. An update of the International Society 
of Sexual Medicine's guidelines for the diagnosis and treatment of premature ejaculation (PE). J Sex Med 2014;11:1392422. [CrossRef]

8. Luján S, García-Fadrique G, Morales G, Morera J, Broseta E, Jiménez-Cruz JF. Are urology residents ready to treat premature ejaculation after their training? J Sex Med 2012;9:404-10.

9. Abdo $\mathrm{CH}$, Afif-Abdo J, Otani F, Machado AC. Sexual satisfaction among patients with erectile dysfunction treated with counseling, sildenafil, or both. J Sex Med 2008;5:1720-6.

10. McMahon CG, Stuckey BG, Andersen M, Purvis K, Koppiker N, Haughie $S$, et al. Efficacy of sildenafil citrate (Viagra) in men with premature ejaculation. J Sex Med 2005;2:368-75. [CrossRef]

11. Polat EC, Ozbek E, Otunctemur A, Ozcan L, Simsek A. Combination therapy with selective serotonin reuptake inhibitors and phosphodiesterase-5 inhibitors in the treatment of premature ejaculation. Andrologia 2015;47:487-92. [CrossRef]

12. Mattos RM, Marmo Lucon A, Srougi M. Tadalafil and fluoxetine in premature ejaculation: prospective, randomized, doubleblind, placebo-controlled study. Urol Int 2008;80:162-5. [CrossRef]

13. Abu El-Hamd M. Efficacy and safety of daily use of tadalafil in treatment of patients with premature ejaculation: $A$ randomised placebo-controlled clinical trial. Andrologia 2018;50:e13005. [CrossRef]

14. La Vignera S, Condorelli RA, Mongioi LM, Calogero AE. Chronic Administration of Tadalafil Improves the Symptoms of $\mathrm{Pa}$ tients with Amicrobic MAGI: An Open Study. Int J Endocrinol 2017;2017:3848545. [CrossRef]

15. Dell'Atti L, Galosi AB, Ippolito C. A randomized single-center study to compare the efficacy and tolerability of tadalafil once daily plus lidocaine anesthetic spray on premature ejaculation. Eur Rev Med Pharmacol Sci 2017;21:1036-40.

16. Ozcan L, Polat EC, Onen E, Kocaaslan R, Otunctemur A, Cekmen $M$, et al. Effects of Tadalafil 5 mg Dosed Once Daily in Men with Premature Ejaculation. Urol Int 2017;98:210-4. [CrossRef]

17. Sato Y, Zhao W, Christ GJ. Central modulation of the NO/ cGMP pathway affects the MPOA-induced intracavernous pressure response. Am J Physiol Regul Integr Comp Physiol 2001;281:R269-78. [CrossRef]

18. Jen PY, Dixon JS, Gosling JA. Co-localization of nitric oxide synthase, neuropeptides and tyrosine hydroxylase in nerves supplying the human post-natal vas deferens and seminal vesicle. Br J Urol 1997;80:291-9. [CrossRef]

19. Jain NK, Patil CS, Singh A, Kulkarni SK. Sildenafil-induced peripheral analgesia and activation of the nitric oxide-cyclic GMP pathway. Brain Res 2001;909:170-8. [CrossRef]

20. Corona G, Rastrelli G, Limoncin E, Sforza A, Jannini EA, Maggi M. Interplay Between Premature Ejaculation and Erectile Dysfunction: A Systematic Review and Meta-Analysis. J Sex Med 2015;12:2291-300. [CrossRef]

21. MJ Dresser, D Desai, S Gidwani, AD Seftel and NB Modi. Dapoxetine, a novel treatment for premature ejaculation, does not have pharmacokinetic interactions with phosphodiesterase- 5 inhibitors. International Journal of Impotence Research 2006;18:104-10. [CrossRef]

22. Fugl-Meyer K, Fugl-Meyer AR. Sexual disabilities are not singularities. Int J Impot Res 2002;14(6):487-93. [CrossRef] 